\title{
XLVIII. Hints respecting a new theory on the orbits of comets
}

\author{
Mr. W. Crane
}

To cite this article: Mr. W. Crane (1810) XLVIII. Hints respecting a new theory on the orbits of comets, Philosophical Magazine Series 1, 36:150, 253-256, DOI: $10.1080 / 14786441008563185$

To link to this article: http://dx.doi.org/10.1080/14786441008563185

曲 Published online: 18 May 2009.

Submit your article to this journal $\pi$

Џ Article views: 2

Q View related articles $\sqsubset$ 
Hints respecting a New Theory on the Orbits of Comets. 253

produced by the heat of the season, which would naturally cause the wind to rush thither, with all its contents, and with greater impetuosity. The coolness of the atmosphere on elevated situations may be ascribed also to the evaporation of the uppermost strata of the clouds, which accompany the land winds.

Many arguments 1 have dispensed with, which might have been produced to elucidate and to establish my thecry, as they were chiefly such as conld be collected from simpie inference, and from affirmative application of doctrines advanced before.

I will only add, that both the sirocco and samiel may be owing to similar causes as those which appear to be productive of the pernicious, or rather disagreeable, eflects of onr land winds.

XLVIII. Hints respecting a New Theory on the Oilits of Comets. By Mr. W. Crane, of Edinlurgh.

To Mr. Tilloch.

SIR, $T_{\text {HE }}$ following theory, for any thing I know, is original: should it be deemed worthy of a place in the Philosophical Magazine, its insertion will much oblige

Sept. 27, 1810 .

Your humble servant,

W. Cranf,

Student of Micdicine, Ediuburgh.

"Hast thou ne'er seen the comet's flaming ficht?

The illustrious strangrer passing, doubles wide

Heaven's mighty capc, and then revisits Earth."-Yoing.

The difficulties with which this intricate branch of astronomy is surrounded, the short part of an orbit of a comet that is visible to $\mathrm{us}$, and the rarity of their appearance, have given rise to innumerable theories, many of which have no sooner been advanced than they were immediately abandoned as erroneous.

The school of Peripatetics assigned comets no place in our planetary system, they only considered them as sublunary things made up of the exhalations in the terrestrial regions; which was the opinion of many, until Tycho Brahe and Kepler proved by observation that they were beyond the moon, and consequently not composed of terrestrial vapours : this was further confirmed by the observations made by Cassini, of that seen in the year 1665 , and of another that appeared in April 1680. Cartesius thought them to be permanent bodies, like the planets, and to be constantly 
carried from one vortex to another in right lines: but Cassini supposed from his observations that they moved in circles very eccentric, and containing the earth's orbit within them; and from hence was led to think the comet of 1650 and 1681 was the same as appeared in 1577. By means of this and some others he had an opportunity of seeing, he determined that comets moved through the constellations Antinons, Pegasus, Andromeda, Taurus, Centaur, Scorpio, and the bow of Sagittarius, which he called the zodiac of comets. That this is not the case, later observations have proved. The comet that appeared in September 1808 was first seen in Serpentarius, it then passed through the right shoulder of Hercules, the Lyre, and disappeared in the tail of the $S$ wan, which is a course widely different from the zodiac laid down by Cassini. James Bernouilli, in his System of Comets, published in 1682, consid:rs them to be satellites moving abuut a primary planet, which revolved around the sun, at a distance equal to 2583 scmidiameters of the Maguus orbis, in four years and $15 \%$ days, although Salurn, who is 258 imes nearer, makes only one revolution in about 30 years. This primary, he says, we can never see, on account of its smalluess and immense distance, and these comets or satellutes are only visible when they descend towards us in perigenm. In this theory we have a gredter body revolving round and carricd with a smaller: which is contrary to what is observed with regard to the other planets and their satellites. May we not consider this as one of those theories which, had it not come from so great a nan, would have been buried long ago in oblivien?

Sir Isaac Newton, Dr. David Gregory, Dr. Hallev, and others, imarine them to move in vury eccentric ellipses, having the centre of the sun in one of their foci: but some in their calculations have substituted a porion of a parabola having the same vertex and focus, which they observe is its true trajectory, if it never returns. This supposition only leads us from one difficulty to another; for we may next ask, By what means did it come within the attraction of the sun, and from whence? Are we to suppose it passes from one fixed star to another in a serpentine direction, which is the theory adopted by Mr. Cole of Colchester? All the celestial phenomena with which we are acquainted, are obedient to certaiu laws of attraction, and move cither in circles or ellipses, but none in the manner abore mentioned.

Eut to return to the former theory; that is, that they 
move in very eccentric ellipses, in one of the foci of which is placed our sun; for, as La Place says in his System of the World, analogy leads us to imagine that comets move in orbits, which, instead of being nearly circular, like those of the other planets, are very eccentric, and the sun extremely near that part in which they are visible to us; and to observe the same law as the other planets.

Hence is it not probable that they revolve about two fixed stars, placed in the two foci of their orbits? This opinion, I think, is strengthened by the amazing eccentricity of their orbits, which, as was observed above, approaches very near to a parabola, no comet has yet been seen that would answer to an hyperbola : of this amazing distance, the exceeding small part we see before a comet approaches the sun, and when it leaves him, would not differ much from a right line. Again, as the two foci of the ellipse in which it moves are so very distant, is it not probable there are two attracting powcrs? that, is one in each focus; and as the attraction of one body begins at the point where the other ends, let us conceive the comet to be put in motion a little beyond that point, as at $A$, and by the time it arrived at $B$, its centrifugal

force becomes great enough to throw it within the attraction of the focus $D$, which we will sup-

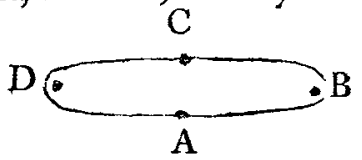
pose at $C:$ it is now acted upon by the attractive power at $D$, and acquires in moving from $C$ to $D$ a velocity great enough to bring it again to $A$; and thus it will revolve about the two fixed stars $\mathrm{B} D$, in a very eccentric ellipse. This will also account for their appearance from every part of the heavens: and it is supposed that more than 450 bave been seen in different directions; for about the same fixed star many may revolve, yet only one about the same two fixed stars.

Ferguson, in his Astronomy, estimates the nearest fixed star at about $32,000,000,000,000$ miles distance from the earth, consequently it is $32000,082,000,000$ miles from the sun; and Adams, in his Astronomical Essays, says that the comet seen by Brydone at Palermo in 1770 noved at the rate of $60,000,000$ miles an hour. Now admitting this to be its average rate, and that it performed a revolution once in 129 years, which is the period assigned to that which appeared in 1661, we shall have 67,802,400,000,000 miles for the length of its orbit; and it is not improbable that this would be the perimeter of an eccentric ellipse whose foci were the distance above mentioned. 


\section{Machine for securing Persons attempting Depredations}

All Nature is held together by an universal bond: the vegetable kingdom is joined to the animal by the sensitive plant; birds and fishes by the bat and beaver; the monkey joins beast to men ; and the sun by his vast infuence hinds the worlds together that form our system. Let us extend our views a little further, and we shall have the blazing comet uniting the systems of other suns to ours, forming the links of that chain by which the universe is supported.

XLIX. Description of a Machine for securing Persons attempting Depredations without affecting their Life or Limbs. By Mr. Robert Salmon, of Woburn*

SIR, I beg leave to submit to the Society of Arts, \&rc. a mantrap, which I hope will meet with their approbation. To those who live in the country it is needless to explain the frequency of petty depredations committed on gardens, orchards, \&c. and which are sometimes very vexatious. Few persons would like to endanger the life or limb of the depredator by setting the common steel man -trap, yet it is presumed there are but few who would not wist to detect the offender. The instrument which I have the honour to submit to the Suciety is for the purpose of catching and holding the person without injury. At the Agricultural Mceting at Woburn last summer, an ingenious invention for a similar purpose was produced by Sir Theophilus Biddulph; it consisted of a wood box, containing two springs in iron barrels, and two chains passing over and round them : when this was set, the chains were wibhdrawn from round the barrels, and extended to a cerlain distance. A trigger then kept the trap from closing. The whole was then covered over with thin irm plates; so that if a person set his foot on those plates his leg dropped into the box, and the chains closed round it and held the leg; but as the box was about three feet square and a foot deep, it was requisite that it should at setting be let into the ground, which would be a work of considerable labour, and when done it would be difficult to dispose of the stuff from the hole, or to conccal the trap; and as the whole apparatus was cumbersome and expensive, it appeared to me not to be well applicable in practice.

* From Transactions of the Snciety for the Fencourasement of Arts, Mannfacturs, and $C$ ommerce vol. $x \times$ vii.- The sitver medi! of the Society was voted to Mr. Salmon for this communication, and one of the machines is reserved in the Society's repusitury for the inspcction of the puilic. 